\title{
SPECIAL ISSUE ON RECENT ADVANCES IN LOT SIZING
}

\author{
Kerem Akartunal1 ${ }^{1 *}$, Maristela O. dos Santos ${ }^{2}$, \\ Raf Jans $^{3}$ and Silvio Alexandre de Araujo ${ }^{4}$
}

Production planning aims to efficiently plan the production activities as well as the acquisition of the raw materials and resources required to transform raw materials into finished products, in order to meet customer demand in the most economical way possible. The decisions to be made include, but are not limited to, production lot sizes, setup decisions, work force levels and sequencing of production runs, while the ultimate aim is to determine the optimal timing and level of production.

Lot sizing problems (Pochet \& Wolsey, 2006) arise in many industrial contexts, and in spite of being studied for more than 60 years, the community still faces many challenges in the field, ranging from modeling paradigms to the design and experimental evaluation of efficient methods and algorithms. Some interesting literature reviews on lot sizing problems can be found in Brahimi et al. (2017), Glock et al. (2014), Buschkühl et al. (2010) and Jans \& Degraeve (2008) and the latest special issue was published in 2011 (Clark et al., 2011). In view of its importance and applicability, this special issue of Pesquisa Operacional presents six papers on recent advances in lot sizing.

The authors Maryam Darvish, Martin P. Kidd, Leandro C. Coelho and Jacques Renaud, in the paper entitled "Integrated production-distribution systems: trends and perspectives", provide an excellent review of the existing literature on production and distribution problems. Firstly they present a general overview on sequential versus integrated supply chain functions and problems and, afterwards, they focus on the integrated production-distribution by classifying the reviewed papers in single and multi-product models. The authors identify current research trends and suggest interesting directions for future research.

\footnotetext{
*Corresponding author

${ }^{1}$ University of Strathclyde, United Kingdom - E-mail: kerem.akartunali@strath.ac.uk - http://orcid.org/0000-00030169-3833

${ }^{2}$ Universidade de São Paulo-USP, Brazil - E-mail: mari@icmc.usp.br - http://orcid.org/0000-0003-0822-3439

3 HEC Montréal and GERAD, Canada - E-mail: raf.jans@ @ec.ca - http://orcid.org/0000-0001-8510-5677

${ }^{4}$ Universidade Estadual Paulista Júlio de Mesquita Filho-UNESP, Brazil and GERAD, Canada - E-mail: silvio.araujo@unesp.br - http://orcid.org/0000-0002-4762-2048
} 
João Flávio de Freitas Almeida and Samuel Vieira Conceição, in the paper "A decomposition approach for the two-stage stochastic supply network planning in light of the rolling horizon practice", propose a two-stage stochastic programming model for tactical supply chain planning admitting uncertainty and considering the Sales and Operations Planning under rolling horizon planning. To solve the model a multi-cut Benders decomposition algorithm is proposed. The computational results, based on random data and industrial data from a Brazilian flat steel company, bring interesting insights.

The paper "Integrated lotsizing, scheduling and blending decisions in the spinning industry", authored by Victor C. B. Camargo, Bernardo Almada-Lobo and Franklina M. B. Toledo, present an interesting and challenging industrial planning problem in the spinning industry. Three approaches to solve this complex problem are proposed: an integrated approach, a sequential approach and a partially integrated approach. The different approaches are illustrated on a specific example.

By considering a practical application in the paper industry, the authors Livia Maria Pierini and Kelly Cristina Poldi, in the paper entitled "Lot sizing and cutting stock problems in a paper production process", propose a mathematical model that integrates lot sizing and cutting stock problems. To solve the presented mathematical model a heuristic approach using column generation and relax-and-fix procedures is presented. Computational tests were carried out on randomly generated instances.

In the paper "Decomposition based heuristics for a lot sizing and scheduling problem on multiple heterogeneous production lines with perishable products" the authors Willy A. O. Soler, Maristela O. dos Santos and Kerem Akartunalı tackle an interesting integrated lot sizing and scheduling problem inspired by food industry. They extend a mathematical model from the literature by proposing a facility location reformulation and heuristic approaches composed of two phases. Computational results using a data set from the literature are presented.

Finally, the authors Beatriz E. Villas Boas, Victor C. B. Camargo and Reinaldo Morabito, in the paper "Modeling and MIP-heuristics for the general lotsizing and scheduling problem with process configuration selection", consider an integrated problem where different items can be produced simultaneously using a specific process (alternative operation mode or configuration of the machine). The authors adapt a mathematical model and heuristic approaches from the literature. Computational experiments with data inspired from different industrial sectors are presented.

All the presented papers nicely show that it is very important to integrate the lot sizing problem with other relevant and related problems. In some cases this can be a strategic problem such as network design. In other cases there is a need for integration with more tactical problems such as the production line setup or configuration selection. Finally, some papers show the integration with preceding processes such as blending or cutting stock, or subsequent processes such as transportation. 
We would like to thank the authors who submitted their papers to this special issue, the anonymous referees, and the editor of Pesquisa Operacional and the Brazilian Society of Operations Research who made the edition of this issue possible.

\section{References}

[1] Brahimi N, Absi N, Dauzère-PÉrès S \& Nordli A. 2017. Single-item dynamic lotsizing problems: An updated survey. European Journal of Operational Research, 263(3): $838-863$.

[2] Buschiühl L, Sahling F, Helber S \& Tempelmeier H. 2010. Dynamic capacitated lot-sizing problems: a classification and review of solution approaches. $O R$ Spectrum, 32(2): 231-261.

[3] Clark GeA, Almada-Lobo B \& Almeder C. 2011. Lot sizing and scheduling: industrial extensions and research opportunities. International Journal of Production Research, 49(9): 2457-2461.

[4] Glock CH, Grosse EH \& Ries JM. 2014. The lot sizing problem: A tertiary study. International Journal of Production Economics, 155: 39 - 51.

[5] Jans R \& Degraeve Z. 2008. Modeling industrial lot sizing problems: a review. International Journal of Production Research, 46(6): 1619-1643.

[6] Pochet Y \& Wolsey LA. 2006. Production planning by mixed integer programming. Springer Science \& Business Media.

\section{How to cite}

Akartunali K, Santos MO, Jans R \& De Araujo SA. 2021. Special issue on recent advances in lot sizing. Pesquisa Operacional, 41 (s1): e41s101. doi: 10.1590/0101-7438.2021.041s1.0041s101. 